\title{
The role of spatial scale and background climate in the latitudinal temperature response to deforestation
}

Yan Li et al.

Correspondence to: Yan Li (yanli.geo@gmail.com)

The copyright of individual parts of the supplement might differ from the CC-BY 3.0 licence. 


\section{Supplementary figures:}
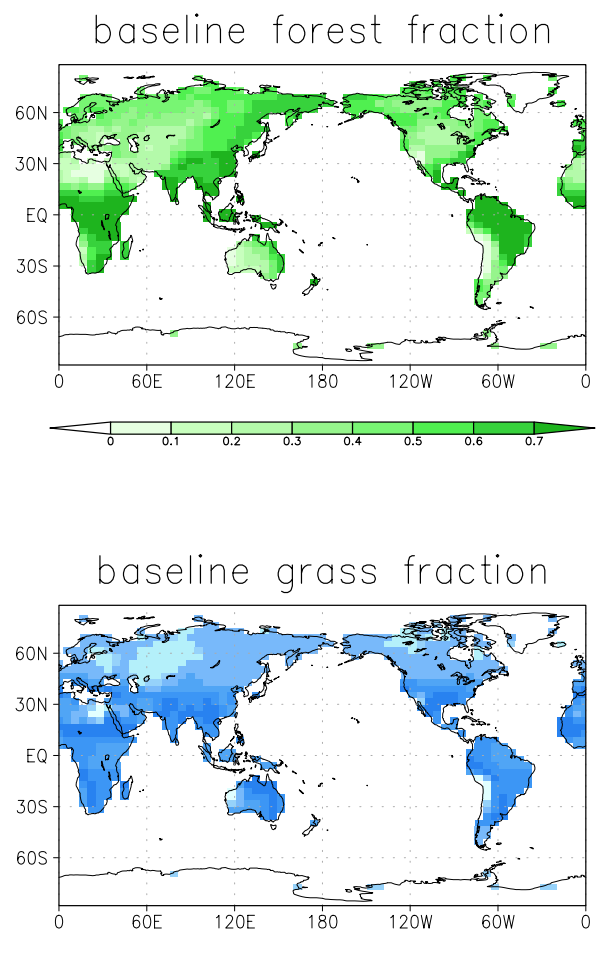

5

Figure S1. Simulated vegetation distribution in the control experiment (CTL) 


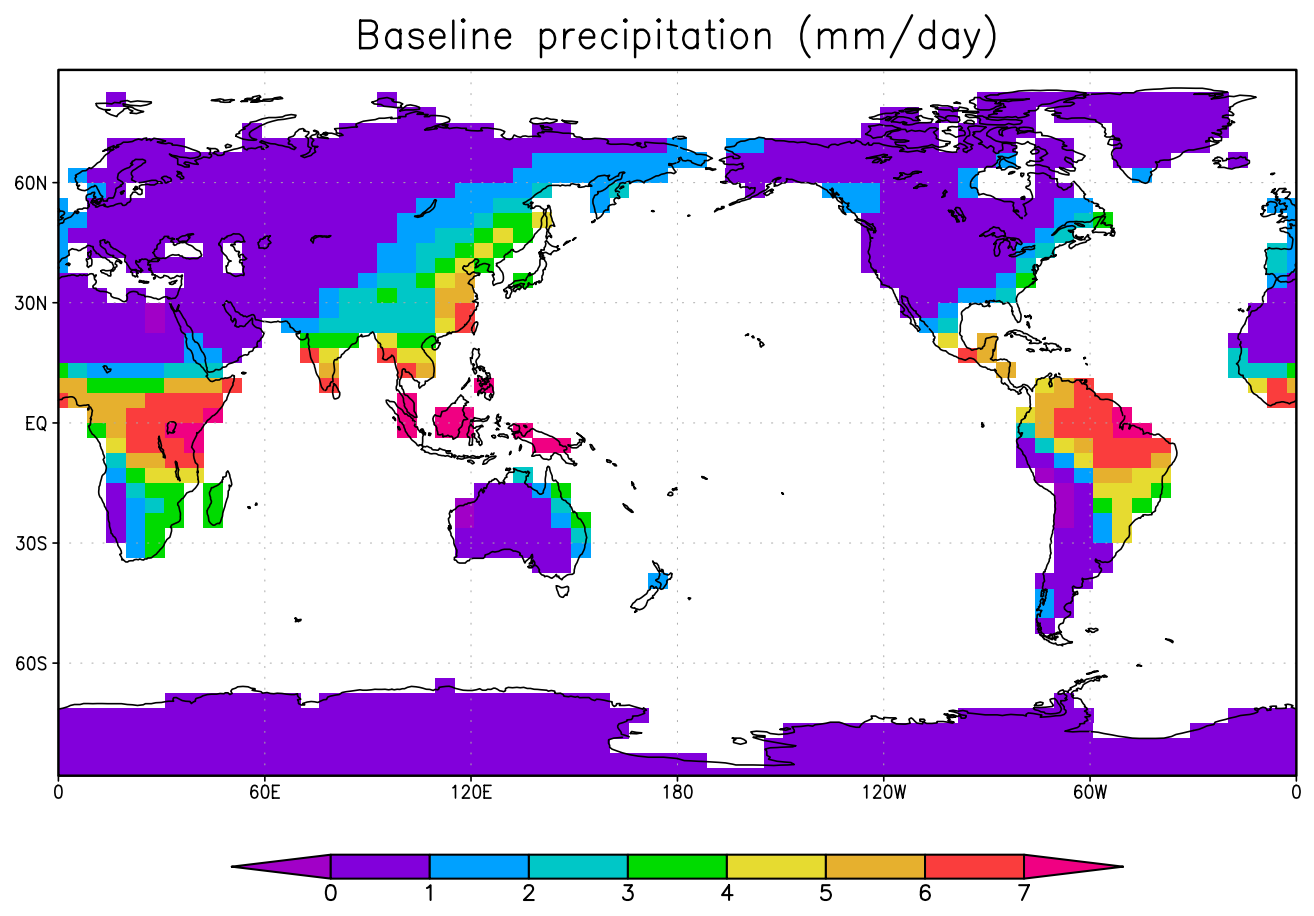

14

Figure S2. Annual mean precipitation simulated in the control experiment 

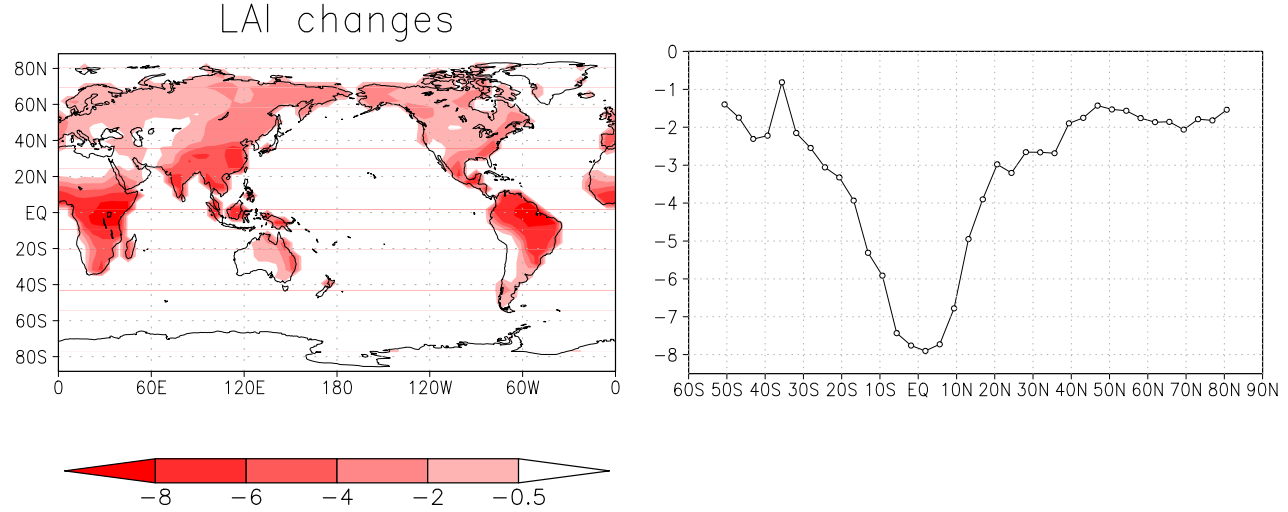

Figure S3. Spatial (left) and latitudinal (right) patterns of LAI changes due to global deforestation (Unit: $\mathrm{m}^{2} / \mathrm{m}^{2}$ ) 


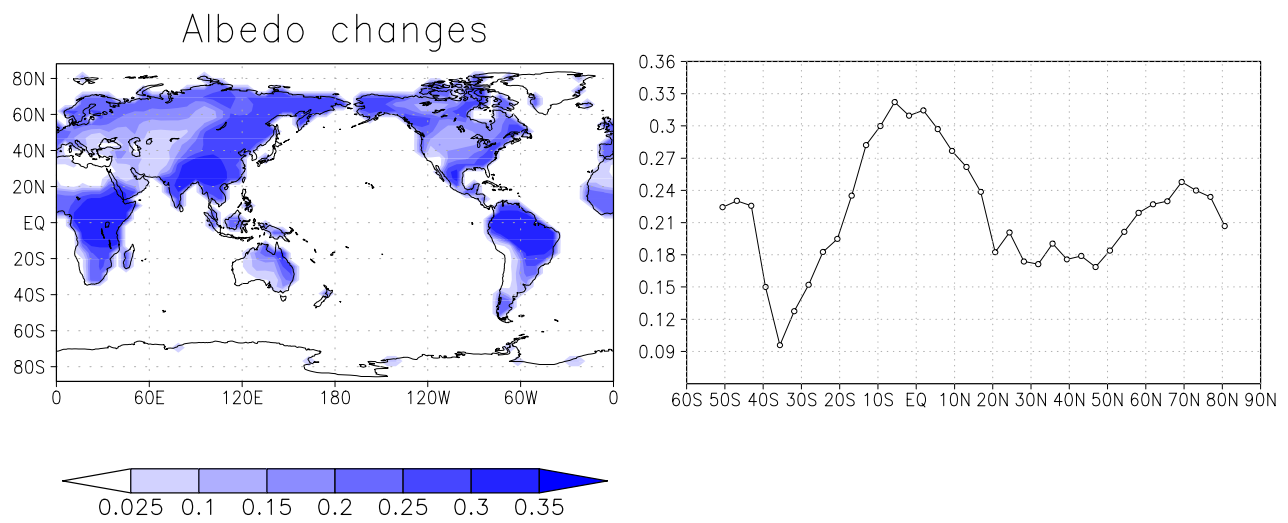

Figure S4. Spatial (left) and latitudinal (right) patterns of albedo changes due to global deforestation 


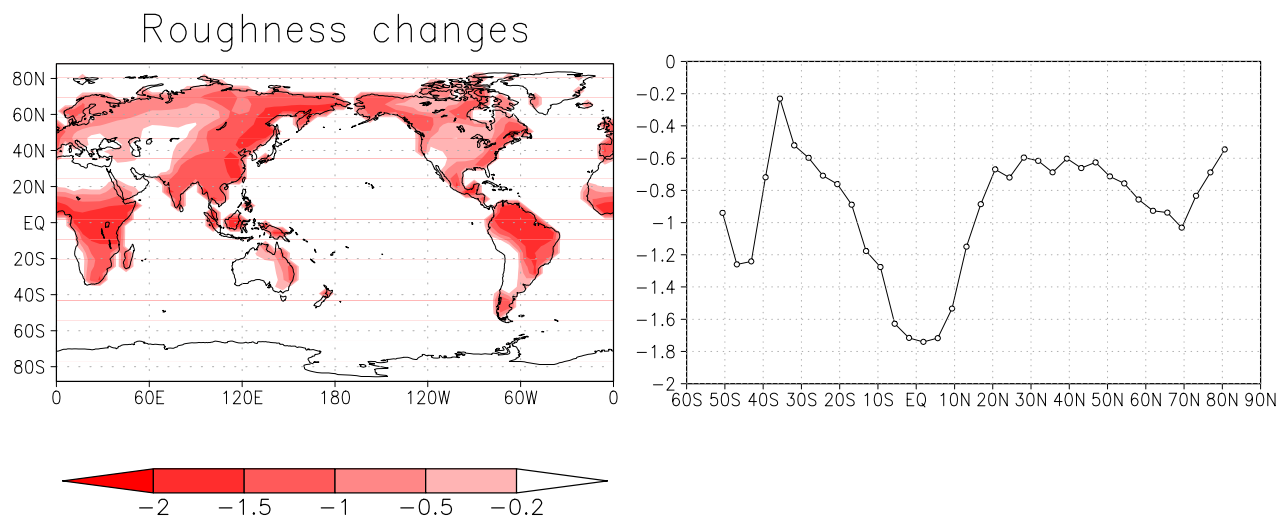

Figure S5. Spatial (left) and latitudinal (right) patterns of roughness changes due to global deforestation (Unit: $\mathrm{m}$ ) 

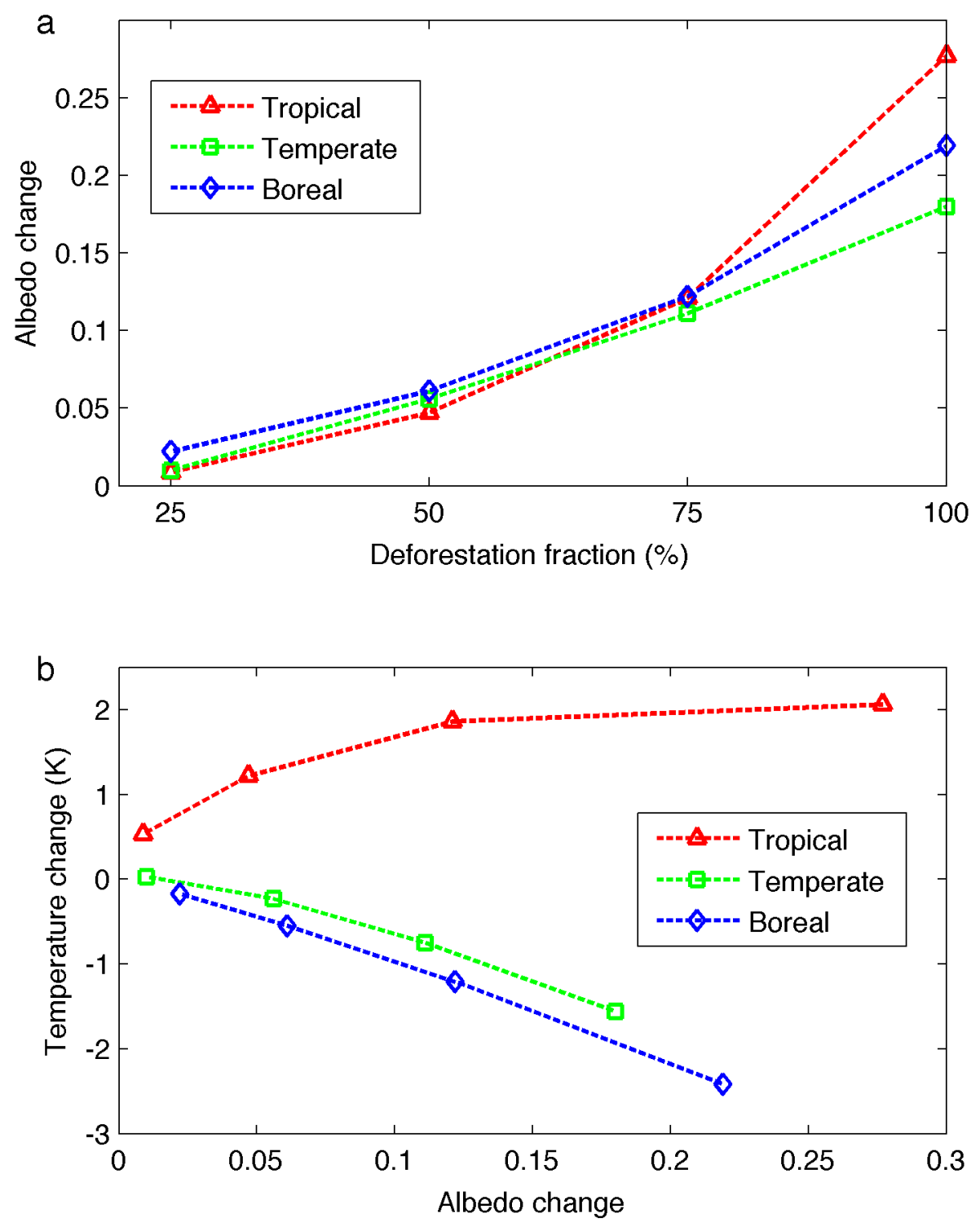

Figure S6. (a) Response of albedo change to growing deforestation fraction from $25 \%$ to $100 \%$ and (b) temperature response to albedo change under different deforestation fractions. Data points in the figure are from Table 3. 


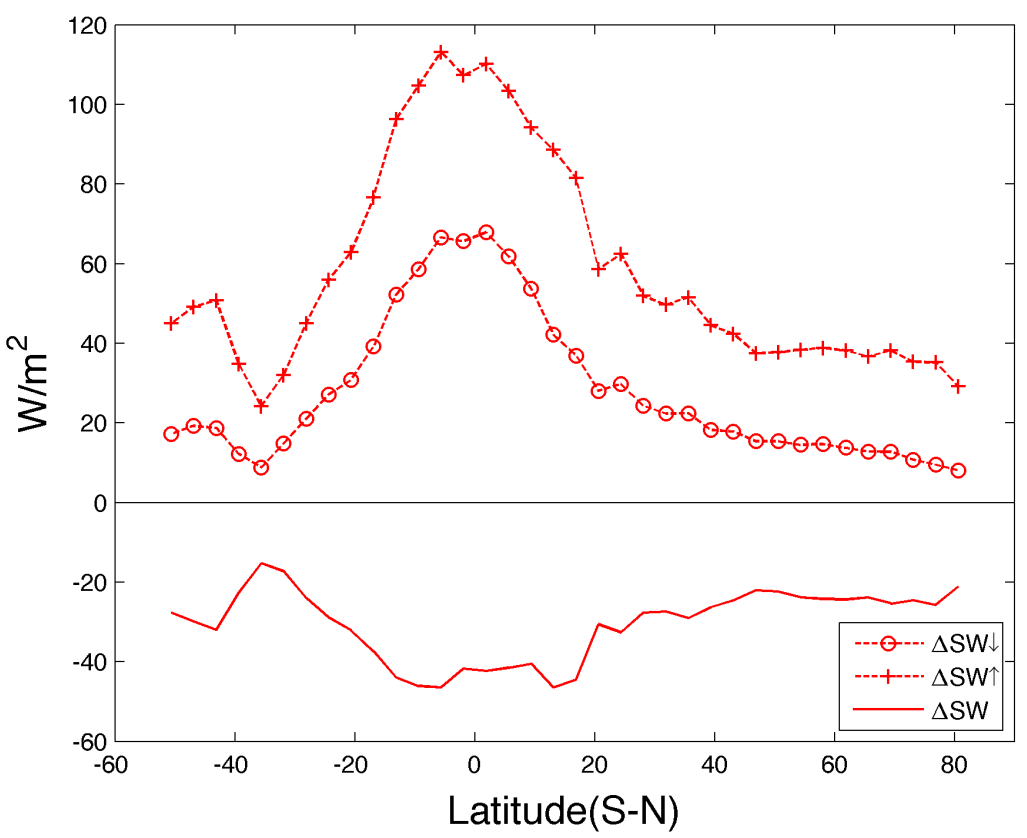

16

Figure $\mathrm{S} 7$. Latitudinal changes in downward $(\Delta \mathrm{SW} \downarrow)$, upward $(\Delta \mathrm{SW} \uparrow)$ and absorbed shortwave radiation $(\Delta \mathrm{SW})$ 


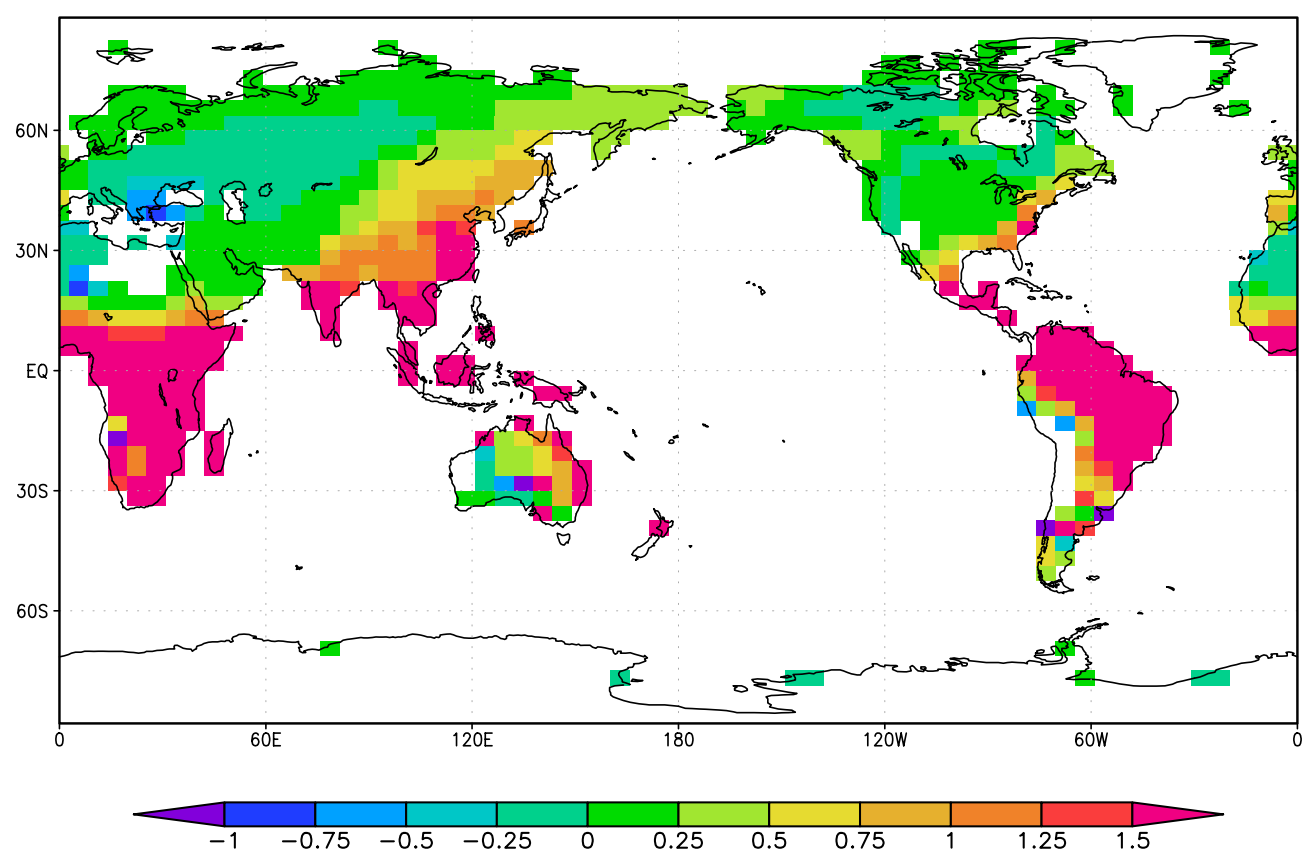

Figure S8. Ratio of $\Delta \mathrm{ET} / \Delta \mathrm{SW}$ in global deforestation 

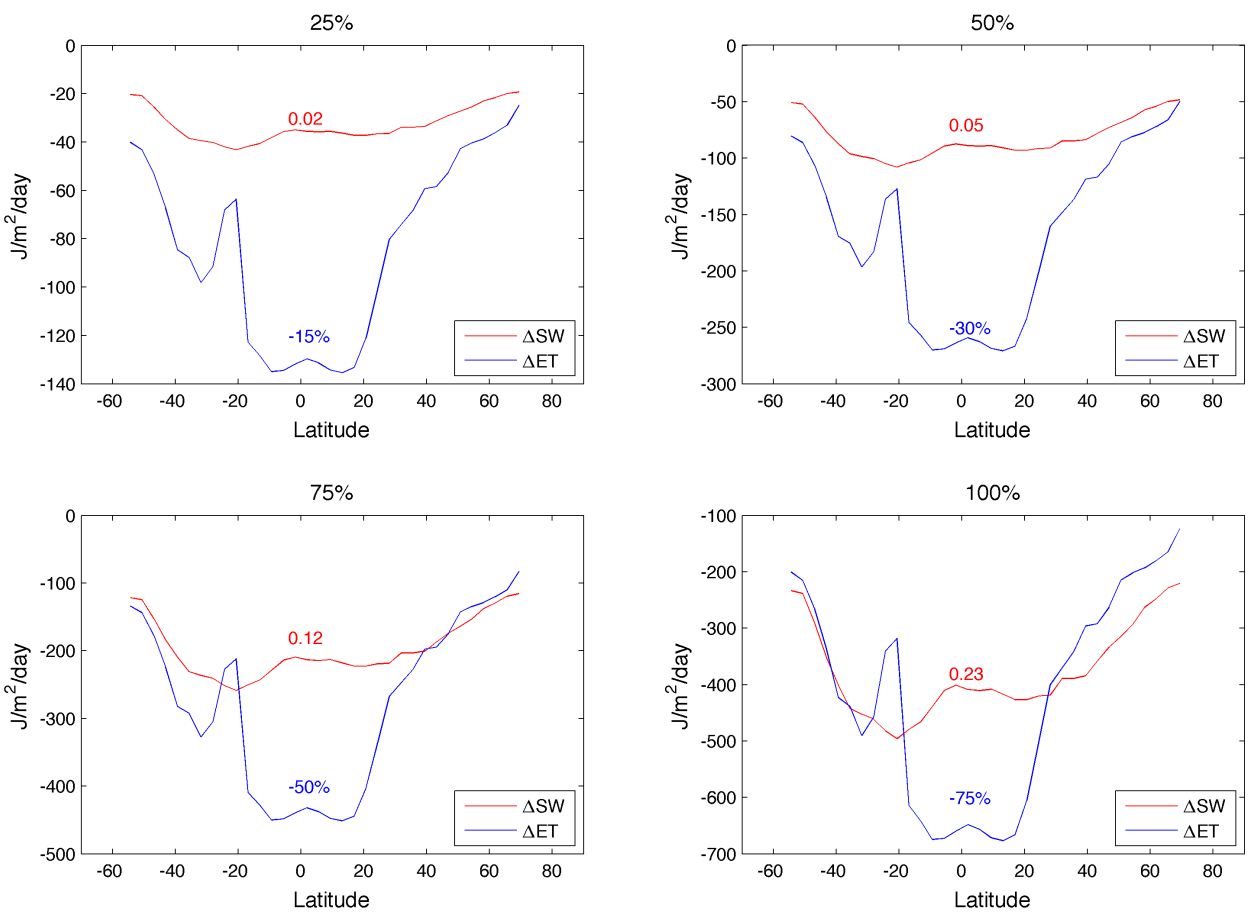

17

Figure $\mathrm{S} 9 . \Delta \mathrm{SW}$ and $\triangle \mathrm{ET}$ calculated with MODIS ET and shortwave radiation (data from

Li et al. (2015))

18

19

20

21 